\title{
Improving the mechanical efficiency of a Pelton Wheel impulse turbine at Low head during operation
}

\author{
P. B. Sob \\ Department of Mechanical Engineering, Faculty of Engineering and Technology, \\ Vaal University of Technology, Vanderbijlpark 1900, Private Bag X021, South Africa.
}

\begin{abstract}
In this paper an approach to improve the performance of a Pelton wheel impulse turbine at very low energy head was investigated for efficient and stable power generation during electrical power generation. During operation gravitational energy of the elevated water into mechanical energy is being converted into electrical energy by water that strikes the vanes which rotate the runner for an electromagnetic force (emf) to be generated which produced electricity. This require a process of kinetic energy produced by the water jet which is directed tangentially to the buckets of the Pelton wheel and usually the jet energy is used to propelled the rim of the buckets for power generation. Usually this process is more convenient for high water head application as it required high kinetic and potential energy from the source during operation due to high energy heads during operation. For over the year's hydroelectric power generation is reported to have low energy and efficiency during low heads since the buckets speed is very low and the kinetic energy is very low to power the wheel. Most often materials used to design the vanes and runner are very heavy which increases the weight of the vanes and the runner during operation. For the runner and the vanes to rotates faster even at low head the weight of the vanes and runner must be minimise for the runner and vanes to have the desire high speed even at very low energy head during operation. In the current study the weight of the runner and vanes are reduced to test the energy produced at low head and the strength of the vanes and runner tested if it was carry the load at the reduced weight during operation. The discharge produced by the jets was able to power the vanes and the runner at very low head. Consequently, this designed Pelton wheel turbine will open a new horizon for hydro power plants in central and West Africa during dry season when energy generation is very low, since sufficient energy can be generated even at very low energy head due to the low weight of the vanes and runner.
\end{abstract}

Keywords: Pelton-wheel, performance, kinetic energy, potential energy, gravitation and Jet-propulsion

\section{INTRODUCTION}

Hydroelectricity is very common in West and Central Africa when energy of a falling water strikes the buckets which rotates a runner and convert mechanical energy into electrical energy [1-15]. Usually the amount of stored hydroelectricity is directly proportional to the height and amount of water level [1-13]. This water must strikes the buckets at very high heads for the buckets to move at a very high speed for high electrical efficiency to be generated during operation. This water flow from the dam through the penstock into the jet which strikes the vanes that rotates the turbines and mechanical energy is converted into electrical energy [1-7]. The efficiency of the system is usually very high if the water level in the dam is very high and very low if the water level in the dam is very low [110]. Therefore the energy generated depend on the water level in the dam, which is directly related to the height of water in the dam which translate to the potential energy and kinetic energy [1-17].

When the moving fluid acts on the van blades there is a reaction of flow from the van blade and this imparted the rotational energy of the rotor which moves in a magnetic field from the impulse turbine [1-13]. In the current study the water from the dam must flow at a very low head to the impulse turbine for the Pelton wheel to generate electricity [1-13]. The Pelton wheel is designed as a tangential free flow jet impulse turbine which uses a jet nozzle usually under very high heads to hit the vanes that rotates at a very high speed for the relevant kinetic energy to be produced to power the shaft of the turbine. The jet momentum striking the runner is affected and the velocity of water at the tangential point of entry is assumed to be zero and all the produced kinetic energy are converted to mechanical energy to produce high mechanical, hydraulic and over efficiency. This require velocity of the turbines which is affected by the impact of the jet discharge and the weight of the vanes and runner that have been reduced for efficient speed even at very low head of water supply.

The Pelton wheel experience great velocity along the turbine reaction since the impulse turbines operating principle is based on the concept of velocity due to direction of fluid from the jet. During operating the turbine rotates and generate energy that drive the velocity of water in the jet from the nozzle into the buckets which rotates the shaft for electricity to be generated. In most of the current study the weight of the vanes and runner are very heavy. This heavy weight can only rotate faster if water strikes the vanes at very high head. Therefore for low energy head the power generated is very low since the runner and vanes cannot rotates to generate the desire energy. The characteristic describes newton's second law of motion as the turbine spins and remove kinetic energy of the fluid. There is a change in pressure due to change in velocity head by the 
accelerating fluid through the nozzle. This has to deal with force which deals with weight of the moving body. The high pressure of water is channel through the penstock to the nozzle which strikes the vanes to rotate the shaft. Due to modification of the Pelton wheel for over the years by designing the buckets to release water that will increase the speed of the runner to produce power [7-17] in conventional Pelton wheel. The jet release water which strikes the buckets or vanes and the vanes rotate the runner which convert the water energy into mechanical energy. The vanes are design that they deflect water away from the jet and for over the year's improvement on the Pelton wheel has been on the vanes design to improve the efficiency of the jet Pelton wheel during operation [1-8]. Usually the nozzle design in the penstock is to increase the discharge of water which increases the kinetic energy of water in the penstock which increase the speed of vanes to increase the speed of the runner [1-10]. Therefore this is an indication that increasing the design of the Pelton when and vanes always increases the efficiency of the impulse turbine increases whenever there is an increase in speed of the runner. Therefore the vanes must rotate at high speed if the runner must run at fast speed to increase energy and the system efficiency. From the expression of the hydraulic system $P=\eta \rho Q g H$, where, $\mathrm{P}$ is the mechanical power produced at the turbine shaft in watts. $\eta$ is the hydraulic efficiency of the turbine. $\rho$ is the density of the water in $\mathrm{kg} / \mathrm{m} 3 . \mathrm{g}$ is the acceleration due to gravity in $\mathrm{m} / \mathrm{s} 2$. Q is the volume flow rate passing through the turbine in $\mathrm{m}^{3} / \mathrm{s}$. H is the effective pressure head of water across the turbine in meter which corresponds to the head of water supply to power the runner for mechanical power to be generated [1-17]. It must be recall that in any Pelton wheel the mechanical power can be improve or modify modelling the given equation parameters by means of changing $\eta, Q$ and $H$ inputs as $g$ and $\rho$ are constants parameter during the operation of the Pelton wheel when power is being generated [1-17]. In the current project the efficiency of the mechanical power of the Pelton wheel is improve by modelling the change in $\mathrm{\eta}, \mathrm{Q}$ and $\mathrm{H}$ for optimal performance and by reducing the weight of the runner and vanes. This will inform the design of a new Pelton wheel which will produced higher electrical energy at very low head and the current problem faced during dry season when water level is usually very low that usually results to low electric energy production will be solve.

\section{METHODOLOGY}

The Pelton wheel was designed by L. A. Pelton as a tangential flow turbine for high heads. Due to climate change and that the head produced by a dam is not always stable due to different seasons that gave different head of water level in the dam [1-17]. The design of the Pelton wheel must be modify to operate efficiently under varying operating heads [1- 14]. Therefore to design a Pelton wheel which is efficient and stable the main parts of the turbine which are nozzle and flow regulating arrangement, the runner and buckets, and the breaking jet must be taken into consideration in modelling [1-17]. The fundamental model in a turbine which gives the relationship between mechanical power produced at the turbine shaft in watts $(\mathrm{P})$, the hydraulic efficiency of the turbine $(\eta)$, the density of the water in $\mathrm{kg} / \mathrm{m} 3(\rho)$, the acceleration due to gravity in $\mathrm{m} / \mathrm{s}^{2}(\mathrm{~g})$, the volume flow rate passing through the turbine in $\mathrm{m}^{3} / \mathrm{s}(\mathrm{Q})$ and the effective pressure head $(\mathrm{H})$ of water across the turbine in meter which corresponds to the head of water supply to power the runner for mechanical power to be generated is given as

$$
P=\eta \rho Q g H
$$

From equation [1], the mechanical power produced at the shaft depend greatly on effective pressure head $(\mathrm{H})$. The model of the effective pressure head in a turbine can be derive from the net head or the effective head available at the inlet of the turbine. Generally as water flow from the head race to the turbine, a loss of head due to friction between the water and penstock usually occurs. There are other minor energy losses due to bending, pipe fittings and entrance losses of the penstock which also affect the net head but these minor losses are ignored in the expression of the net head given as

$$
H=H_{g}-\frac{4 x f x \mathrm{~L} x V^{2}}{D x 2 g}
$$

Where $\mathrm{H}$ is the net head in meter, $H_{g}$ is the gross head in meter, $f$ is the coefficient of friction $\mathrm{L}$ is the length of the penstock in meter, $V$ is the velocity of flow in penstock in $\mathrm{m} / \mathrm{s}$ and $D$ is the diameter of the penstock in meter. This net head affect the all efficiency of the Pelton wheel such as hydraulic efficiency, volumetric efficiency, mechanical efficiency and overall efficiency. The net head also affect the jet velocity, velocity of jet at the inlet, power at the base of the nozzle and speed ratio which affect the power generatedby the Pelton wheel. Since the main objective of the current paper is to develop a Pelton wheel that can generate good power at a very low head it was important to study the head turbine head generated to the vanes and power produce by the vanes.

The net head generated translate to the effective speed of the runner of the Pelton wheel. This speed is propel by the nozzle which produced water which strikes the vanes which rotates the runner. For the runner to move at low net head and low pressure of water the weight of the runner must be minimise. Therefore weight of the vanes and the runner must be minimise for high efficiency of power generation at low head. Weight plays a significant part in energy optimisation. For energy to be minimise the weight of most mechanical system must be reduce. In automotive and airspace industries the weight has been reduced to improve energy savings. Therefore the idea of reducing weight to improve energy in the Pelton wheel must be investigated. In the current study theweight of the vanes and the runner have been reduced to increase mechanical efficiency in the Pelton wheel. Figure 1 revealed the current system under investigation in the current study. 
International Journal of Engineering Research and Technology. ISSN 0974-3154, Volume 13, Number 7 (2020), pp. 1508-1515

(C) International Research Publication House. https://dx.doi.org/10.37624/IJERT/13.7.2020.1508-1515

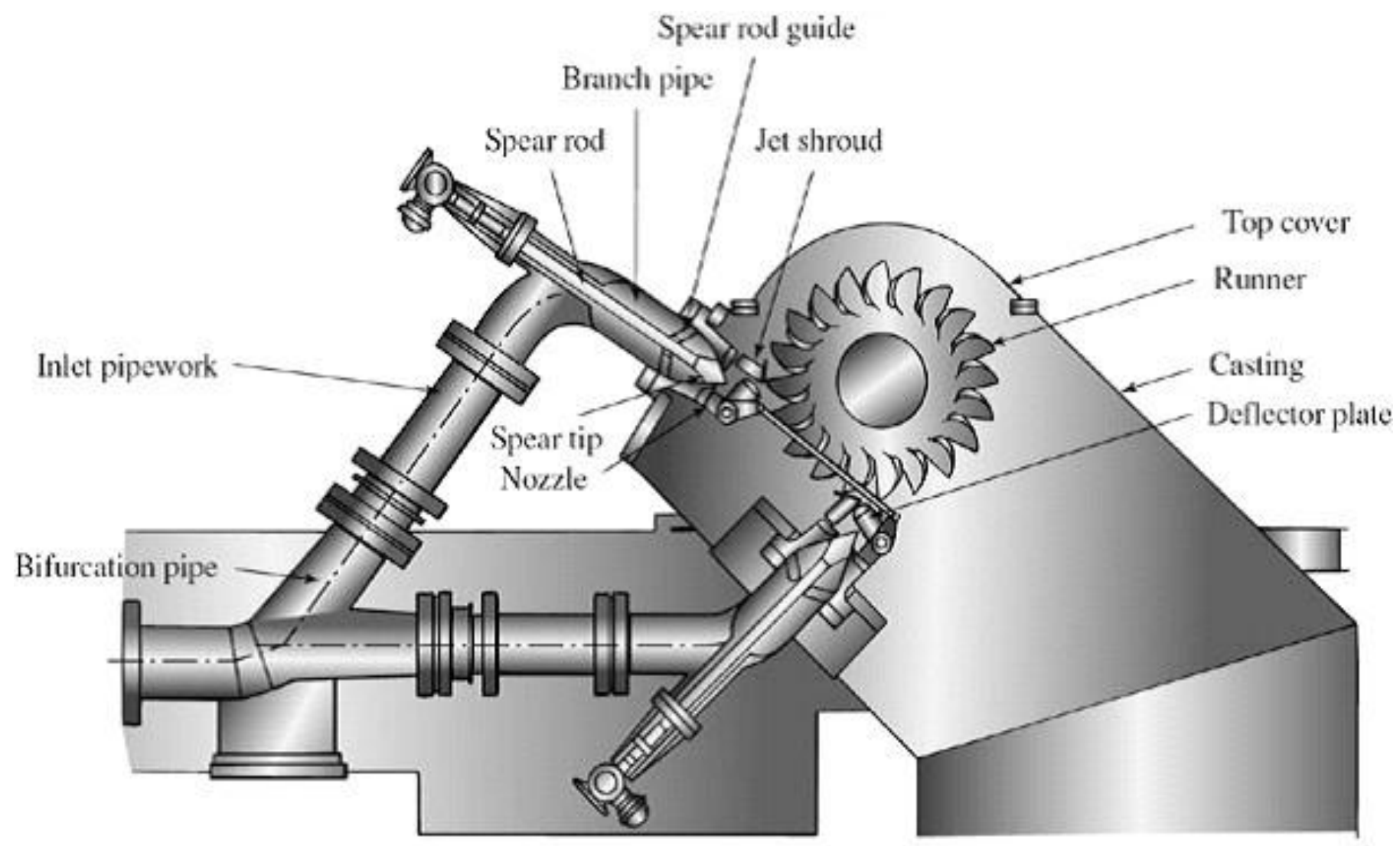

(a)

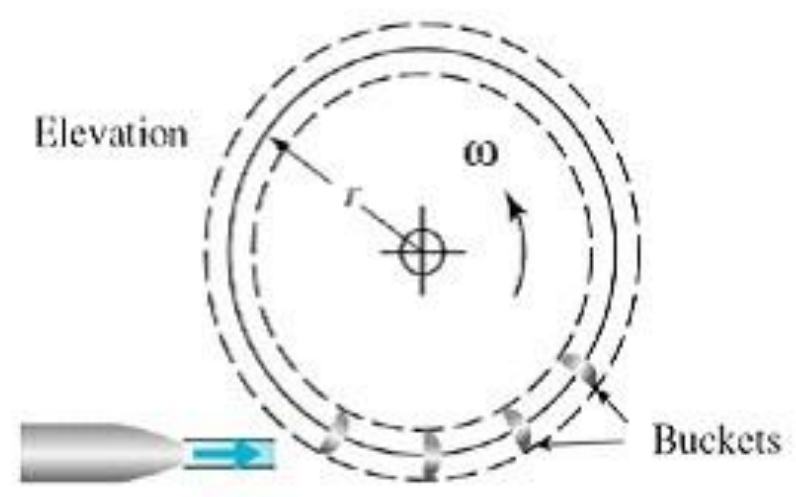

Plan view of jet striking one bucket

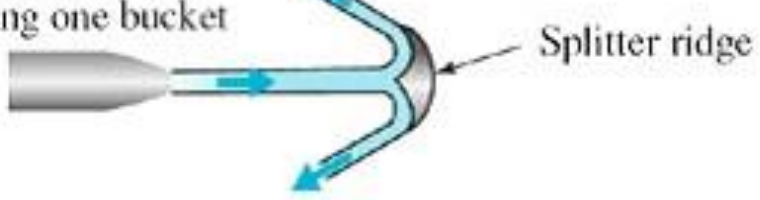

Figure 1: Pelton wheel system showing the vanes and runner during operation

The weight of the vanes and runner are studied at very low head to improve the efficiency of the turbine. The two materials which are mild steel used for the runner and aluminium alloy used for the vanes are simulated in the current study to test their strength and energy generated at very low head for optimal performance. 


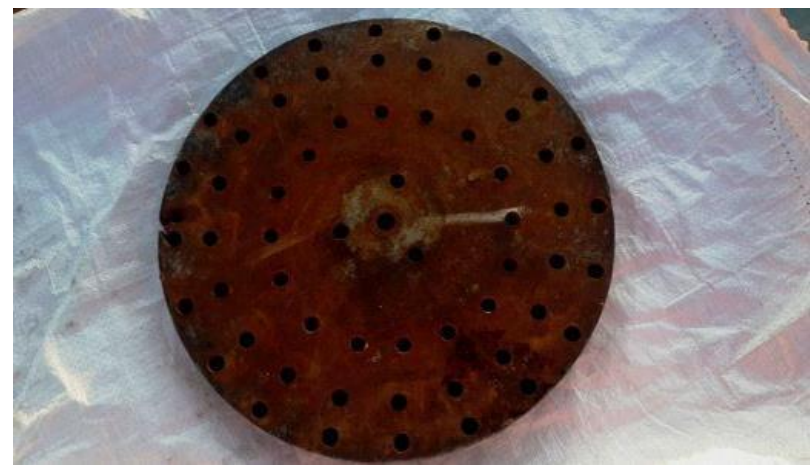

(a)

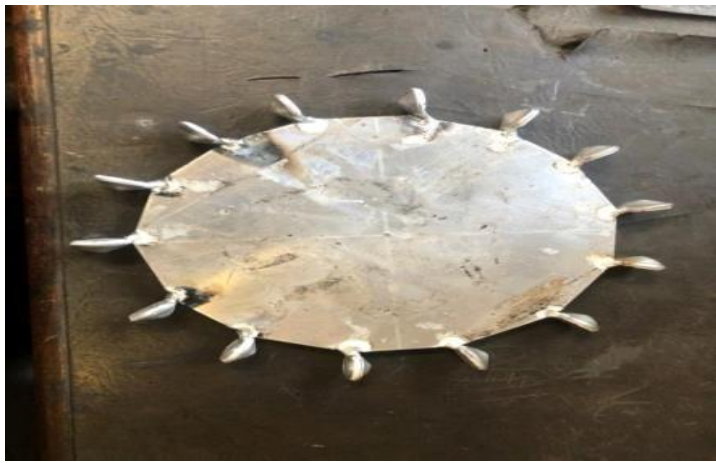

(b)

Figure 2 (a). mild steel used for the runner (b). aluminium alloy used for the vanes

The mild steel used in the study has a plate thickness of $10 \mathrm{~mm}$. The weight of runner which is $3.5 \mathrm{Kg}$ was simulated to test their stress/strain distribution during operation under different operating low heads of water. Using FEA using ANSYS Workbench 12.0 for the theoretical simulation the results are presented from Figure 3 to Figure 6.

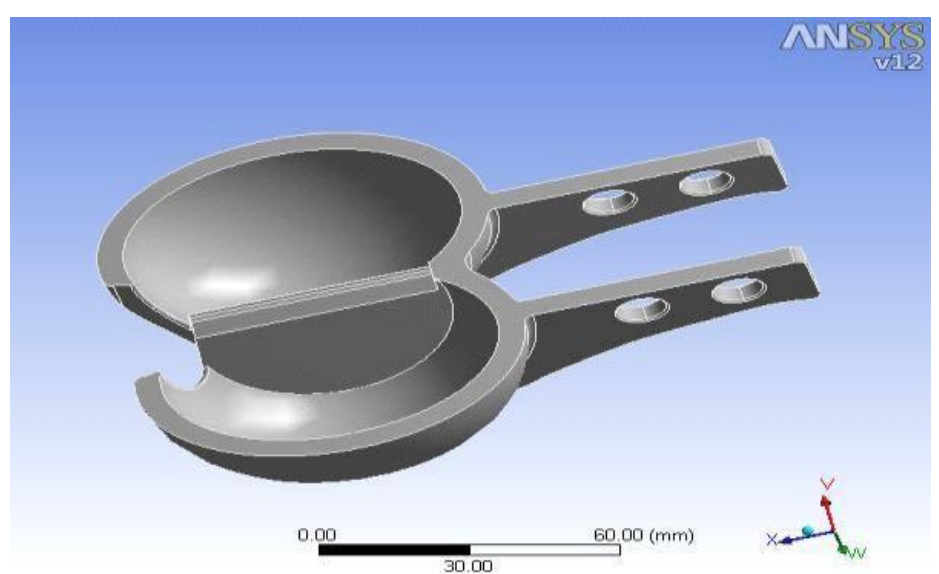

(a)

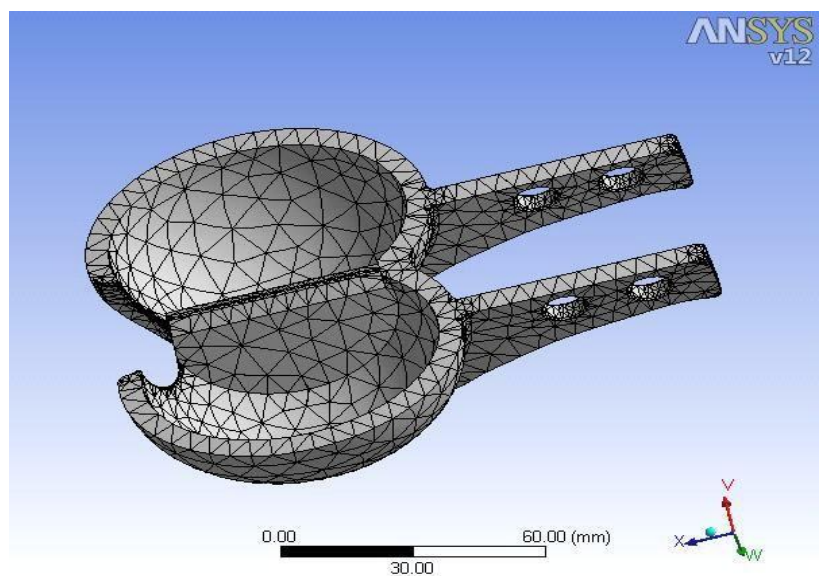

(b)

Figure 3 (a) the bucket ANSYS model (b) model statistic load distribution

Table 1: Statistics of bucket

\begin{tabular}{|c|c|}
\hline Statistics & Quantity \\
\hline Bodies & 1 \\
\hline Active Bodies & 1 \\
\hline Nodes & 18758 \\
\hline Elements & 10151 \\
\hline
\end{tabular}

Figure 3 revealed the reduced weight of the vanes after theoretical simulation and table 1 give the bucket statistic of the design vanes at reduced weight. The simulated vanes shown that the produced vane can withstand the stress/strain being imparted by water in the vane during operation. It also shows that there is uniform distribution of stress and strain in the produced vanes. It was important to show the stress and strain relationship during operation of the vanes and the runner during operation at low and very high head.
Table 2: Properties of aluminium alloy

\begin{tabular}{|c|l|l|}
\hline S No & \multicolumn{1}{|c|}{ Properties } & \multicolumn{1}{|c|}{ Values } \\
\hline 1 & Density & $2700 \mathrm{~kg} / \mathrm{m} 3$ \\
\hline 2 & Compressive Yield Strength $(\mathrm{MPa})$ & 280 \\
\hline 3 & Tensile Ultimate Strength $(\mathrm{MPa})$ & 310 \\
\hline 4 & Young's Modulus $(\mathrm{MPa})$ & 71000 \\
\hline 5 & Poisson's Ratio & 0.33 \\
\hline
\end{tabular}

Table 3: Model Static Structural Loads

\begin{tabular}{|c|c|}
\hline Type & Force \\
\hline X Component & $0 . \mathrm{N}$ (ramped) \\
\hline Y Component & $5 . \mathrm{N}$ (ramped) \\
\hline Z Component & $0 . \mathrm{N}$ (ramped) \\
\hline
\end{tabular}




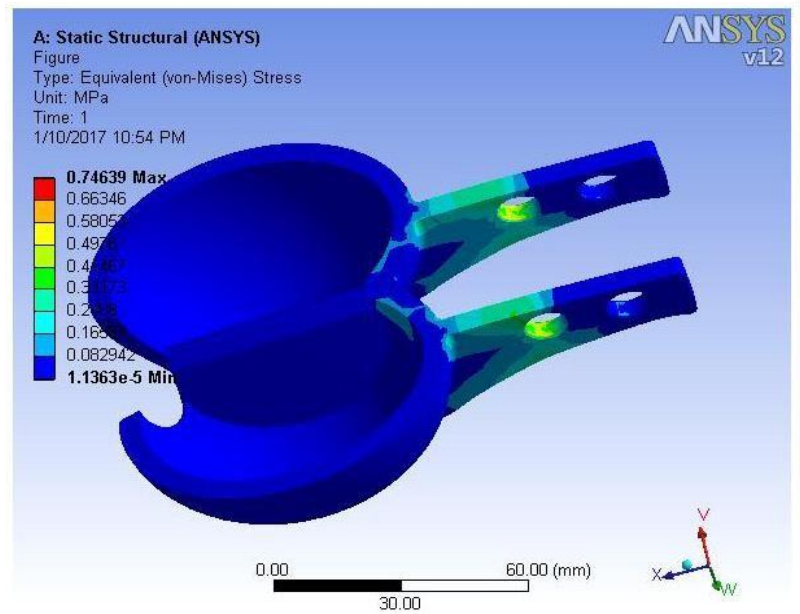

(a)

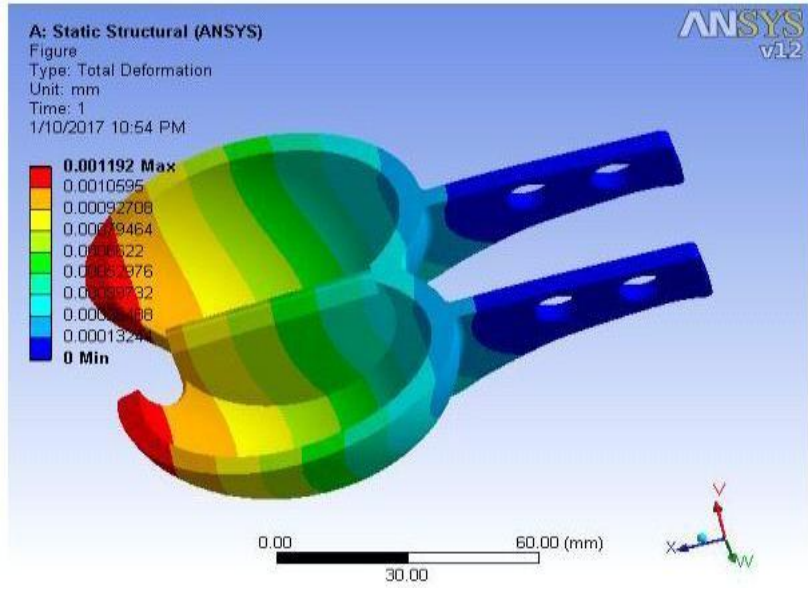

(b)

Figure 4 (a)deformation of bucket during operation (b) total deformation of bucket during operation

The results in figure 3 revealed the stress and strain relationship at very high head during vane operation. Table 2 revealed the property of aluminium used to produce the vanes and table 3 revealed the load applied in the vane in the different direction during operation. Figure 4 (a) revealed the vane stress and strain relationship at very low head during the vane operation and figure 4 (b) revealed the vane stress and strain relationship at very high head during vane operation. It is shown that the vane will operate better at very low energy head without any fear of material failure as shown in Fig.4 (a). This is due to the fact that there is no stress and strain deformation suffered by the vane at very low energy head. At very high energy head the vane will have high stress and strain deformation at the tip of the vanes as shown in Fig. 4 (b) and the materials can easily suffer from material failure due to very high stress concentration at the tip of the vane. Therefore the produced vane can operate better at very low head but the possibility of vane failure at very high energy head is likely to take place as shown in Fig. 4 (b). It was important to look at the equivalent stress, minim and maximum deformation range of the vane during operation as shown in table 4 . However it was also important to analyse the weight of the runner and vanes during operation and study their impact on stress and strain at low and high head during operation.

Table 4: Model Static Structural Solution Results

\begin{tabular}{|c|c|c|}
\hline Type & $\begin{array}{c}\text { Equivalent } \\
\text { (von-Mises) } \\
\text { Stress }\end{array}$ & $\begin{array}{c}\text { Total } \\
\text { Deformation }\end{array}$ \\
\hline Minimum & $1.1363 \mathrm{e}-005 \mathrm{MPa}$ & $0 . \mathrm{mm}$ \\
\hline Maximum & $0.74639 \mathrm{MPa}$ & $1.192 \mathrm{e}-003 \mathrm{~mm}$ \\
\hline
\end{tabular}

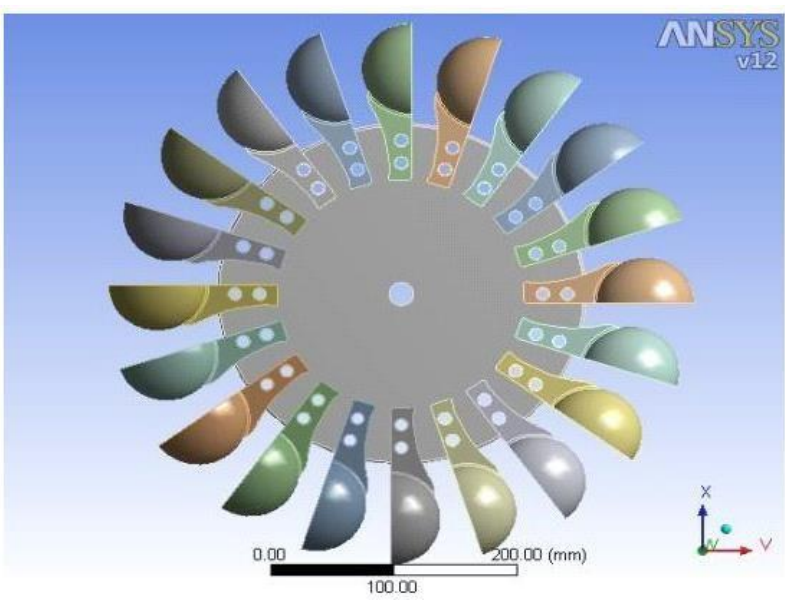

(a)

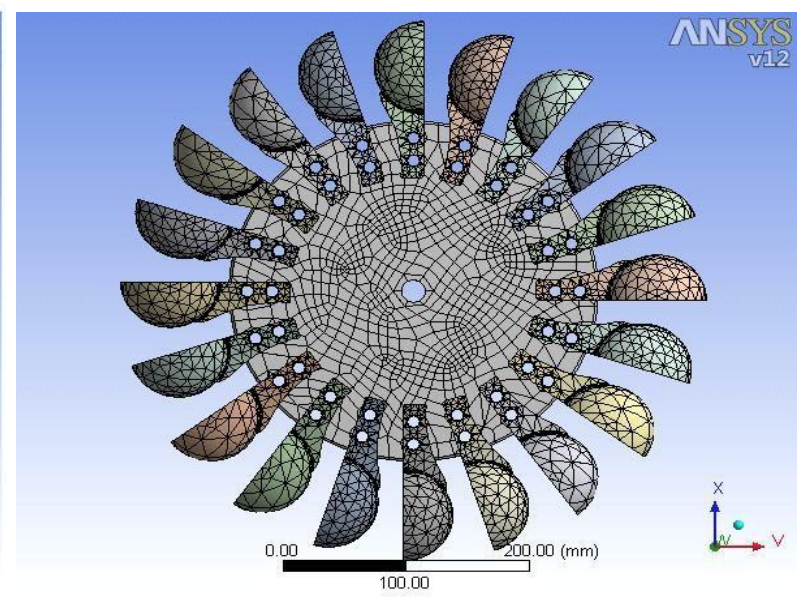

(b)

Figure 5 (a). Full assembly ANSYS model of Pelton runner (b). Meshing of Pelton runner Table 5 Statistics of assemble parts 
International Journal of Engineering Research and Technology. ISSN 0974-3154, Volume 13, Number 7 (2020), pp. 1508-1515

(C) International Research Publication House. https://dx.doi.org/10.37624/IJERT/13.7.2020.1508-1515

Table 5: Statistics of assemble parts

\begin{tabular}{|l|l|}
\hline Statistics & Quantity \\
\hline Bodies & 110 \\
\hline Active Bodies & 21 \\
\hline Nodes & 195780 \\
\hline Elements & 101911 \\
\hline & \\
\hline
\end{tabular}

Table 6: Properties of Runner

\begin{tabular}{|l|l|l|}
\hline S No & Properties & Values \\
\hline 1 & Density & $7200 \mathrm{Kg} / \mathrm{m} 3$ \\
\hline 2 & $\begin{array}{l}\text { Compressive Yield Strength } \\
(\mathrm{MPa})\end{array}$ & 240 \\
\hline 3 & Young's Modulus $(\mathrm{MPa})$ & 10000 \\
\hline 4 & Poisson's Ratio & 0.28 \\
\hline
\end{tabular}

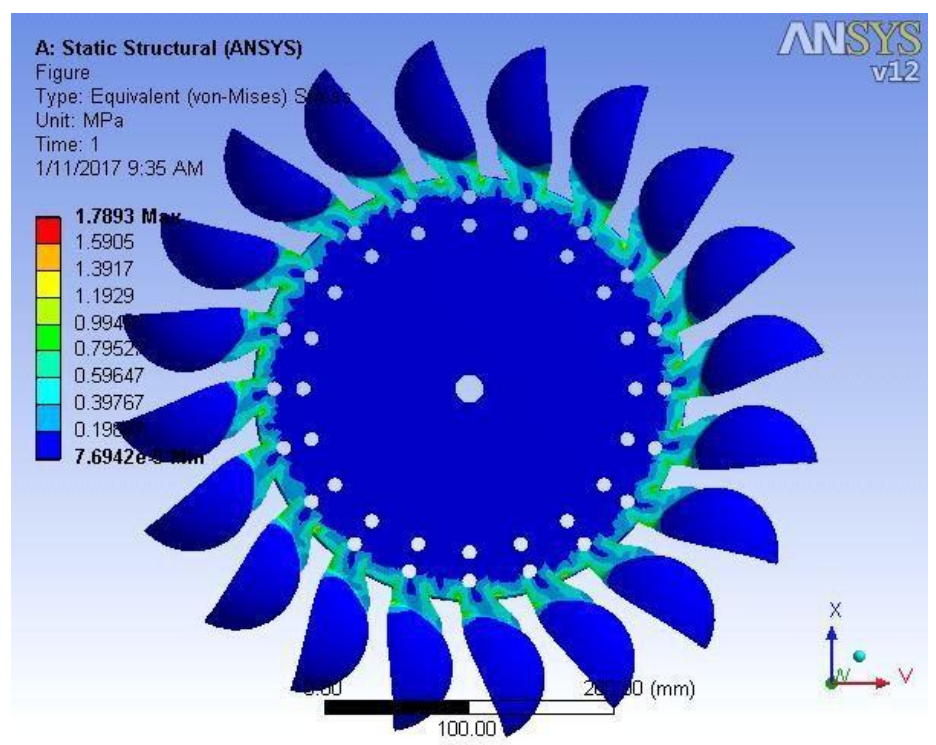

(a)
Table 1: Model Static Structural Solution Result

\begin{tabular}{|c|c|c|}
\hline Type & $\begin{array}{c}\text { Equivalent } \\
\text { (von-Mises) Stress }\end{array}$ & $\begin{array}{c}\text { Total } \\
\text { Deformation }\end{array}$ \\
\hline Minimum & $7.6942 \mathrm{e}-005 \mathrm{MPa}$ & $0 . \mathrm{mm}$ \\
\hline Maximum & $1.7893 \mathrm{MPa}$ & $3.2376 \mathrm{e}-003 \mathrm{~mm}$ \\
\hline
\end{tabular}

Figure 5 revealed the full assembly ANSYS model of Pelton runner and the Meshing of Pelton runner during operation process. The results in Fig. 5 revealed that the vanes and runner at operating efficiently at low head and the expected energy is produced by the runner and vanes without any fear of material failure due to stress and strain relationship of the vanes and runner during operation at low head. The statistical assemble of the runner, material properties and equivalent stress of the runner is shown in table 5, table 6 and table 7 . Therefore the produced vanes and runner are very efficient at low head during operation. It was also important to test the operation of the runner and vanes at high head during operation as shown in Fig.6.

Figure 6 (a) Pelton wheel runner before operation and (b) Equivalent stress of Pelton runner

The results in Figure 6 (a) revealed the stress/strain of the runner and vanes at low head and the results of Fig. 6 (b) revealed the runner and the vane at high energy head. One thing is very clear from observation is that the runner can withstand the stress/strain experience by high and low pressure without any material failure or deformation. It is also shown that the vanes is likely to suffer from deformation at the extern end during high head operation. There are also different control input for the distinctive runner materials of Pelton wheel turbine. The speed of fly, release and control yield were found and this test was performed on Stainless steel, Cast press, Gentle steel and Aluminium fabric of runner. These perusing are given underneath within the table: To begin with setup is on the Stainless steel material runner which could be a strong plate of $10 \mathrm{~mm}$ thickness. 
International Journal of Engineering Research and Technology. ISSN 0974-3154, Volume 13, Number 7 (2020), pp. 1508-1515

(C) International Research Publication House. https://dx.doi.org/10.37624/IJERT/13.7.2020.1508-1515

Table 2: Result on changing on speed of runner due to velocity variation on Stainless steel runner

\begin{tabular}{|c|c|c|c|c|c|c|c|}
\hline S No & Discharge (m3/s) & Velocity (m/s) & Power input (Watt) & RPM & u & Power output & Efficiency \\
\hline 1 & 0.001246 & 2.32 & 3.35 & 117.8 & 1.84 & 1.172 & 64 \\
\hline 2 & 0.001655 & 2.96 & 7.25 & 156.5 & 2.45 & 1.654 & 56 \\
\hline 3 & 0.001721 & 3.17 & 8.64 & 172.1 & 2.71 & 1.552 & 49 \\
\hline
\end{tabular}

Table 3: Result on changing on speed of runner due to velocity variation on cast iron runner

\begin{tabular}{|c|c|c|c|c|c|c|c|}
\hline S. No & Discharge (m3/s) & Velocity (m/s) & Power input (Watt) & RPM & $\mathrm{u}$ & Power output & Efficiency \\
\hline 1 & 0.001246 & 2.32 & 3.35 & 122.5 & 1.92 & 0.977 & 56 \\
\hline 2 & 0.001655 & 2.96 & 7.25 & 159.5 & 2.5 & 1.492 & 51 \\
\hline 3 & 0.001721 & 3.17 & 8.64 & 179.4 & 2.81 & 1.214 & 39 \\
\hline
\end{tabular}

It can be observed from table 8 that as the discharge increases the runner speed also increased. The efficiency of the system was reported to increase and the power output also increase during operation. The maximum runner speed was noticed as $172.1 \mathrm{RPM}$ at $0.001721 \mathrm{~m} 3 / \mathrm{s}$ discharge and $3.17 \mathrm{~m} / \mathrm{s}$ jet velocity. This indicate an increase in power generated by the system at very low energy head. Another test setup was done on cast press fabric runner which is additionally a strong plate but of $10 \mathrm{~mm}$ thickness and we are taken two plates of $10 \mathrm{~mm}$ and $9 \mathrm{~mm}$ crevice is filled by the washer for lessening the weight of runner. It was important to study the changing speed of the runner and their velocity during operation.

The results in table 9 was done on the same setup utilized but a diameter of $10 \mathrm{~mm}$ thick cast press plate were utilized. These two plates were associated with washer and the crevice between the plates and was kept up at $9 \mathrm{~mm}$. The result shown lower efficiency during operation when compared to table 8 .

\section{CONCLUSION AND RECOMMENDATION}

The current study was aimed at improving the efficiency and performance of a Pelton wheel turbine at very low head. In order to achieve this the energy at low head and weight of runner and vanes were optimised for efficient energy generation without material failure during the vane operation. It was shown that reducing the weight of the vanes after theoretical simulation improve energy and power generation at very low head. It was also shown that there is uniform distribution of stress and strain in the produced vanes at very low head. It was also shown that the vane will operate better at very low energy head without any fear of material failure. This is due to the fact that there is no stress and strain deformation suffered by the vane at very low energy head as revealed in the study. It was also revealed that at very high energy head the vane will have high stress and strain deformation at the tip of the vane and the materials can easily suffer from material failure due to very high stress concentration at the tip of the vane. Therefore the produced vane can operate better at very low head with high energy generation but the possibility of vane failure at very high energy head is likely to take place though with higher energy generation.

\section{ACKNOWLEDGEMENT}

This material is based on the work which is supported financially by the Vaal University of Technology (VUT).

\section{REFERENCES}

[1] Shigley, J. E. and Michke, C. R. "Mechanical engineering design”, eighth edition, 2008 (Tata McGraw Hill, New Delhi, India).

[2] Norton, R. L. "Machine design: an integrated Approach", third edition, 2006 (Pearson Education, Upper Saddle River, NJ).

[3] Shafts Unit no. 7 IGNOU. "http://www.ignou.ac.in/upload/Unit-7-60".

[4] R.E.PETERSON, "Stress Concentration Factor", third edition, 2011(A Wiley interscience publication).

[5] Saleh A. Al-Fozan, Anees U. Malik and Mohammad AlHajri "Failure Analysis of Sheared Shaft of a Brine Recycle Pump", Troubleshooting Technical Report No. TSR 3804/05005 in August 2005

[6] E. Rusiński, J. Czmochowski, P. Moczko "Failure reasons investigations of dumping conveyor breakdown" Volume 23 Issue 1 July 2007Journal of Achievements in

[7] Deepan Marudachalam M.G, K.Kanthavel, R.Krishnaraj "Optimization of shaft design under fatigue loading 
International Journal of Engineering Research and Technology. ISSN 0974-3154, Volume 13, Number 7 (2020), pp. 1508-1515

(C) International Research Publication House. https://dx.doi.org/10.37624/IJERT/13.7.2020.1508-1515

using Goodman method" International Journal of Scientific \&

[8] Sandeep Bhattacharyya "Failure analysis of gas blower shaft of a blast furnace" Engineering Failure Analysis 15 (2008) 349-355 Osman Asi "Fatigue failure of a rear axle shaft of an automobile" Engineering Failure Analysis 13 (2006) 1293- 1302

[9] R.W. Fuller a, J.Q. Ehrgott Jr. b, W.F. Heard b, S.D. Robert b, R.D. Stinson b, "Failure analysis of AISI 304 stainless steel shaft" Engineering Failure Analysis

[10] V.S. Rocha, "Fracture failure analysis of gearbox shaft" Vol. 24, Engineering Failure Analysis, 2012

[11] Chun-Yuan Lin Jui-Pin Hung Tze-

[12] Chi Hsu, "Failure Analysis of Reverse Shaft in the Transmission System of All-Terrain Vehicles" ASM International 2008F. Vodopivec et al. "Cracking and fracture of valve shafts in the secondary steam circuit of a nuclear power plant. A case investigation". Nuclear Engineering and Design (2001).

[13] Iradj Sattari-Far et al. "Failure of stainless digester shafts in a paper production plant" Engineering Failure Analysis (2003).

[14] Y.J. Li et al. "Fracture analysis of a castellated shaft" Engineering Failure Analysis (2007).

[15] Y.J. Li et al. "Fracture analysis of a castellated shaft" Engineering Failure Analysis

[16] A.H.V. Pavan et al. "Root cause analysis of bowl-mill pinion shaft failures" Case Studies in Engineering Failure Analysis 1 (2013) 103-109

[17] $Z$. Domazet et al. "Failure of two overhead crane shafts" Engineering Failure Analysis 44 (2014) 125135 . 